\title{
Synthetic approaches towards avibactam and other diazabicyclooctane $\beta$-lactamase inhibitors
}

Received 00th January 20xx, Accepted 00th January 20xx

DOI: $10.1039 / x 0 x x 00000 x$

\author{
Laure Peilleron, ${ }^{a}$ Kevin Cariou, ${ }^{* a, b}$
}

Avibactam is a non $\beta$-lactam $\beta$-lactamase inhibitor that has recently been approved in association with a $\beta$-lactam antibiotic for the treatment of severe infections caused by otherwise resistant bacteria. Its therapeutic success encouraged the development of many congeners based on its particular diazabicyclooctane scaffold. This review presents a detailed overview of the synthetic strategies that have been implemented to acces these complex bicyclic compounds with a particular focus on those that are currently on the market or in clinical trials.

\section{Introduction}

The discovery of penicillin G by Sir Alexander Fleming in 1928 was the beginning of a "Golden Age" for antibiotics, especially between the 40s and the 70s. ${ }^{1}$ However, their over-, and sometimes unwise, utilization has led to an increased apparition and dissemination of resistance phenomena in bacteria, that led the WHO to warn against the imminent beginning of a "postantibiotic era". ${ }^{2}$ In particular, many resistance mechanisms target $\beta$-lactam antibiotics, which are among the most prescribed worldwide, such as the production of $\beta$-lactamase enzymes that hydrolyze the $\beta$-lactam nucleus, thus effectively inactivating the antibiotic. In order to overcome these resistances, two strategies can be envisioned. ${ }^{3}$ One is to develop new generations of antibiotics. For example, after penicillins, cephalosporins, carbapenems and monobactams were successively developed (Figure 1A). Yet, the commercialization of these novel antibiotics was systematically followed by the apparition of resistances and the current antibiotic pipeline contains only a few new $\beta$-lactam compounds, all of them being variants of existing molecules (e.g. cefiderocol ${ }^{4,5}$ and $\mathrm{BAL} 30072^{6}$ that both have a siderophore attached to a known scaffold). Another approach is to fight these resistances, by developing small molecules that, in combination with an antibiotic can preserve or restore its activity, ${ }^{7}$ in particular by inhibiting $\beta$-lactamases (BLS). ${ }^{8}$ While most research had been restricted to $\beta$-lactam-based inhibitor, such as clavulanic acid, non- $\beta$-lactam-based inhibitors are now actively studied (Figure 1B). Since 2012, several new broadspectrum inhibitors of serine $\beta$-lactamases (SBLs) of classes $A$ and $C$ have emerged. ${ }^{9}$ Notably, the diazabicyclooctane $(D B O)^{10}$ avibactam ${ }^{11,12}$ and the boronic ester vaborbactam (RPX7009) ${ }^{13}$ were recently approved by the FDA in combination with ceftazidime and meropenem, respectively.

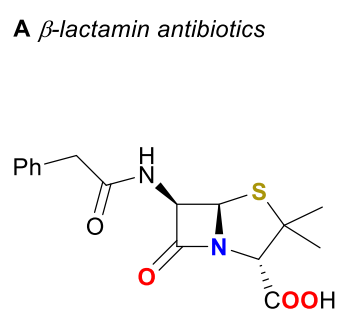

penicillin G, $1943-1945$ penicillin

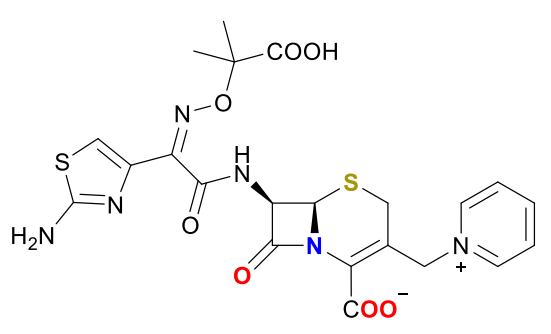

ceftazidime, $1983-1987$ 3rd generation cephalosporin

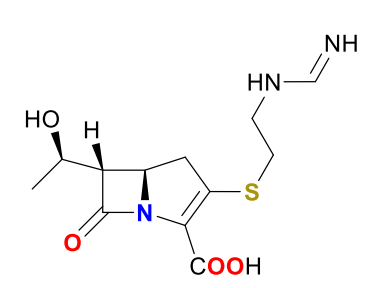

imipenem, 1985 - 1998 carbapenem<smiles>CC1[C@H](NC(=O)/C(=N\OC(C)(C)C(=O)O)c2csc(N)n2)C(=O)N1S(=O)(=O)O</smiles>

aztreonam, 1986 - 1988 monobactam

B approved $\beta$-lactamase inhibitors<smiles>O=C(O)[C@H]1/C(=C/CO)O[C@@H]2CC(=O)N21</smiles>

clavulanic acid, 1985 clavam

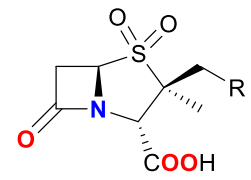

$\mathrm{R}=\mathrm{H}$, sulbactam, 1987 $\mathrm{R}=1$-(1,2,3-triazole), tazobactam, 1992 penam

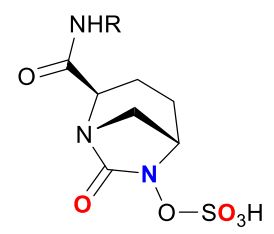

$\mathrm{R}=\mathrm{H}$, avibactam, 2015

$\mathrm{R}=$ 4-piperidinyl, relebactam, 2019

$\mathrm{R}=\mathrm{O}\left(\mathrm{CH}_{2}\right)_{2} \mathrm{NH}_{2}$, nacubactam

$\mathrm{R}=\mathrm{NHCO}$ (3-piperidinyl), zidebactam

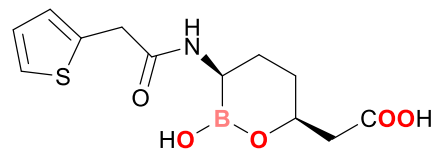

vaborbactam, 2017

Figure 1 Representative examples of $\beta$-lactam antibiotics and $\beta$-lactamase inhibitors (in bold: year on the market; in italic: year of resistance apparition).

\footnotetext{
Université Paris-Saclay, CNRS, Institut de Chimie des Substances Naturelles, UPR

2301, 91198, Gif-sur-Yvette, France. Email: kevin.cariou@cnrs.fr

b. Current address: ChimieParisTech, PSL University, CNRS, Institute of Chemistry for

Life and Health Sciences, Laboratory for Inorganic Chemical Biology, F-75005
}

Paris, France. 
The DBO family is of particular interest as several other congeners such as nacubactam, ${ }^{10}$ zidebactam $^{14}$ or ETX2514 15 are in different stages of preclinical or clinical development and a combination of imipenem, cilastatin and relebactam ${ }^{16}$ (MK7655) was just approved by the FDA in 2019.

The aim of this review is to provide the reader with a comprehensive overview of the synthetic strategies that have been implemented to access $\beta$-lactamase inhibitors (BLIs) and antibiotics of the DBO family. Because these molecules can only be accessed through relatively long and complex multistep synthetic sequences, it showcases how innovative and efficient organic synthesis ${ }^{17-19}$ can provide access to an important class of therapeutic molecules. As more than 150 patents representing more than 3000 molecules can be found from a general structural search (this patent literature was reviewed and summarized in $2010^{20}$ and in 201321), an exhaustive monograph could not be envisaged and we chose to focus mainly on key lead compounds, including FDA approved molecules. Derivatives presenting an original way of access will also be covered. Finally, the details of the mode of action of these compounds will only be briefly presented in the first section to provide a reference frame. Readers wishing to have more insights on these aspect can refer to the seminal review by the group of Schofield: "The road to avibactam: the first clinically useful non- $\beta$-lactam working somewhat like a $\beta$ lactam" and references therein. ${ }^{12}$

\section{Mode of action of avibactam}

Since the majority of the mechanistic studies have been carried out with avibactam, the mode of action of DBO inhibitors will be described with this compound. The inactivation of $\beta$-lactam antibiotics by SBLs occurs through the hydrolysis of the fourmember amide by an active serine residue of the enzyme. DBOs take the place of the antibiotic in the enzyme and the serine attacks the carbonyl of the urea. The increased electrophilicity of this carbonyl is essentially due to the bicyclic framework, whose strained geometry is key for the compound activity. This carbamylation reaction leads to rather stable (compared to an acyl-enzyme complex) carbamoyl-enzyme complex that efficiently block the active site (Scheme 1). ${ }^{11}$ Moreover, unlike $\beta$-lactam inhibitors, that can undergo various rearrangements and fragmentations after the formation of the acyl-enzyme complex, leading to the degradation of the compound, avibactam can be regenerated after reacting with the enzyme. Since the carbamoyl-enzyme complex is not hydrolyzed, it can undergo a slow decarbamylation to revert to avibactam. The stabilization of the complex is also due to several secondary interactions with the polar residues of the cavity. ${ }^{22}$ As evidenced by a crystal structure of the complex with the CTX-M-15, ${ }^{23}$ after the opening of the cyclic urea, the $N$-sulfate group remains in close vicinity of the ester bond formed with Ser-70. Lastly, the primary amide group is located so that it can interact with the water molecules that usually trigger the hydrolysis of the acylenzyme complex that would have been formed with a $\beta$-lactam. These combined effects grant the avibactam-enzyme complex an extended half-life time of more than 7 days for TEM-1 and P99 $\beta$-lactamases, compared to $7 \mathrm{~min}$ for clavulanic acid with the former and $5 \mathrm{~h}$ for tazobactam with the latter. Because of this, only 2-5 molecules of avibactam are sufficient to inhibit 1 enzyme while this ratio is 55:1 for tazobactam against P99 and 214:1 for clavulanic acid against TEM-1. ${ }^{24}$ Additionally, several DBO derivatives can interact not only with SBLs but also with penicillin-binding proteins ( $P B P s)$, thus conferring them intrinsic antibiotic activities. ${ }^{25}$ However, they are inactive against metallo- $\beta$-lactamases (MBLs, class $B$ ) that possess zinc atoms in the active hydrolytic site, such as New Delhi metallo-betalactamase 1 (NDM-1) or Verona integron-encoded metallo- $\beta$ lactamases (VIM). ${ }^{26}$

\section{Synthesis of avibactam}

\subsection{History.}

Avibactam was discovered in the mid-90s by chemists from Hoechst Marion Roussel (HMR). In 1999, HMR became part of Aventis and avibactam was first known as AVE1330A. After the merger with Sanofi-Synthelabo in 2004, Novexel stemmed out

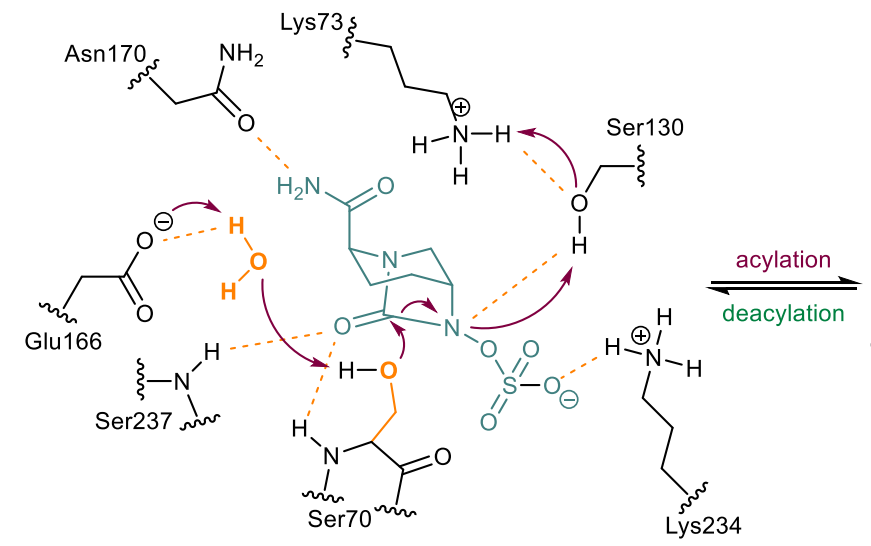$$
\text { Lys234 }
$$

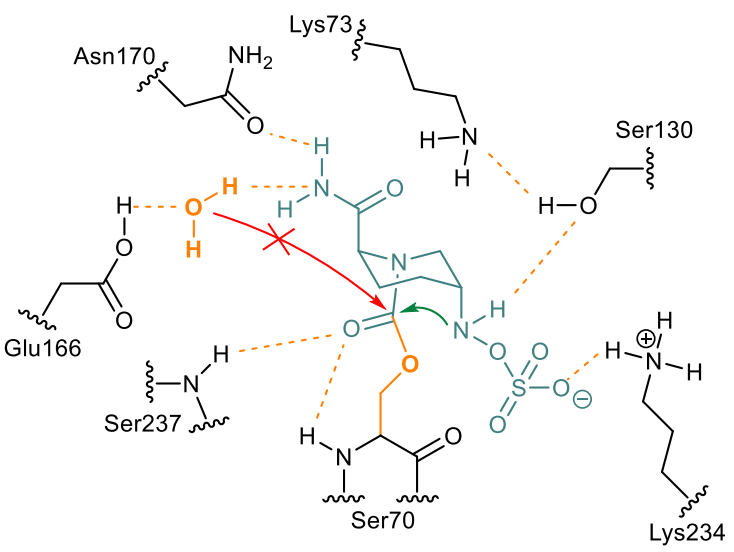

carbamoyl-enzyme complex

Scheme 1 Mechanism of inhibition of the CTX-M-15 $\beta$-lactamase by avibactam and stabilization of the carbamoyl-enzyme complex 
to pursue antibacterial researches and avibactam was then named NXL104. Novexel was eventually acquired by AstraZeneca in 2009. AstraZeneca with Forest Laboratories (later bought by Actavis, now Allergan) jointly developed the combination of avibactam and ceftazidime which was approved by the FDA in 2015 and by the EMA in 2016 under the trade names Avycaz $^{\circledR}$ and Zavicefta ${ }^{\circledR}$.

\subsection{First synthesis.}

The first patents describing the synthesis of avibactam were published in 2002 for the international version ${ }^{27}$ and in 2003 for the US version. ${ }^{28}$ The latter one discloses the original synthesis of avibactam (Scheme 2). It is worth mentioning that this patent does not give any information concerning the absolute configuration of the molecule as only trans and cis are used to differentiate the isomers. The synthesis starts from $N$-Bochydroxy-piperidine 1 (vide infra) which protecting group was first swapped from a Boc to a trifluoroacetate in 3 steps to give 2 with $73 \%$ yield (Scheme 2 ). The trans hydroxylamine was then obtained by a triflation $/ \mathrm{S}_{\mathrm{N}} 2$ sequence using $O$-benzylhydroxylamine to furnish compound 3 with $72 \%$ yield. The trifluoroacetate group was reductively cleaved with sodium borohydride and the resulting free base piperidine 4 was isolated with $55 \%$ after crystallization of its oxalate salt followed by neutralization. The bicyclic derivative 5 was obtained in $89 \%$ yield after treatment with triphosgene. The allyl group was removed by a $\mathrm{Pd}(0)$-catalyzed Tsuji-Trost reaction with sodium ethylhexanoate and the resulting carboxylic acid 6 was converted into primary amide $\mathbf{7}$ via the formation of the mixed isobutyl anhydride. The hydroxylamine group was deprotected by hydrogenolysis of the benzyl group and treatment with $\mathrm{SO}_{3}$ pyridine complex followed by acidification (of the pyridinium salt) gives avibactam. It was then first transformed into its tetra$t$-butylammonium salt $\mathbf{8}$ before going through a sodium ionexchange resin to furnish 9 in 11\% overall yield (16 steps).

Nevertheless, this yield has to be put further into perspective. As no indication of the enantiomeric purity is given, one has to assume that avibactam was isolated as a racemic mixture. Moreover, the synthesis of the key advanced intermediate $\mathbf{1}$ is not described and the inventors mention that it was prepared according to the previous work by C. Beyerman \& P. Boekee. ${ }^{29}$ In this study, diethyl glutamate $\mathbf{1 0}$ was first alkylated to give triester $\mathbf{1 1}$ and the amine was protected as a benzoyl to give $\mathbf{1 2}$ with $70 \%$ yield (Scheme 3 ). A Dieckmann condensation then yielded the mixture of regioisomers 13 \& 13' (75\% combined) that were subjected to acidic conditions to promote a full deprotection and a decarboxylation towards 14, (85\%) which was unfortunately obtained as a racemate. ${ }^{30}$

The piperidine was protected as a benzylcarbamate (15) to avoid the formation of the trans-hydroxyacid $\mathbf{1 6}$ during the reduction. Using sodium borohydride, cis-16 was obtained in $89 \%$ yield. The $\mathrm{Cbz}$ group was cleaved by treatment of a $\mathrm{AcOH} / \mathrm{HBr}$ mixture to give the hydrobromide salt of the amine, which was purified by Amberlite resin treatment to give 17. This 8 steps sequence leads to cis-5-hydroxypipecolic acid $\mathbf{1 7}$ in $39 \%$ yield, from there, the inventors presumably did a Boc protection followed by an esterification to get to key intermediate 1 . This means that the first synthesis of avibactam (as a racemate) effectively required 26 steps, with an overall yield under $4 \%$ that was not suitable for scale-up purposes. Many improvements were then made in order to overcome these limitations, although the general strategy was not deeply altered.<smiles>C=CCOC(=O)C1CCC(O)CN1C(=O)O</smiles>

1. $\mathrm{HCl}, \mathrm{EtOAC}$ 2. $\mathrm{NEt}_{3}$, THF 3. TFAA $( \pm)-1$<smiles>C=CCOC(=O)C1CCC(O)CN1C(=O)C(F)(F)F</smiles>

2, $73 \%$

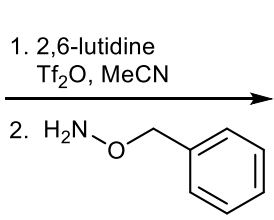<smiles>C=CCOC(=O)C1CC[C@@H](NOCc2ccccc2)CN1C(=O)C(F)(F)C(F)(F)F</smiles>

1. $\mathrm{NaBH}_{4} \mathrm{MeOH},-10^{\circ} \mathrm{C}$ 2. oxalic acid, $\mathrm{THF}$, then $\mathrm{NaHCO}_{3}, \mathrm{THF} / \mathrm{H}_{2} \mathrm{O}$

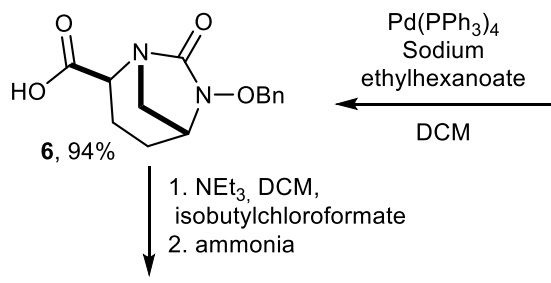<smiles>C=CCOC(=O)C1CCC2CN1C(=O)N2Cc1ccccc1</smiles>

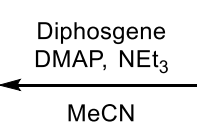<smiles>C=CCOC(=O)C1CC[C@@H](NOCc2ccccc2)CN1</smiles>

1. $\mathrm{H}_{2} \mathrm{Pd} / \mathrm{C}, \mathrm{MeOH}$ 2. $\mathrm{SO}_{3}$-pyridine, pyridine

3. $\mathrm{NaH}_{2} \mathrm{PO}_{4}$ to $\mathrm{pH}=4$ 4. $t \mathrm{Bu}_{4} \mathrm{~N}^{+} \mathrm{SO}_{4} \mathrm{H}-$

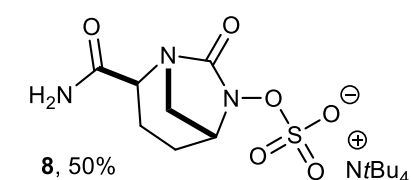

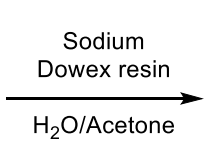

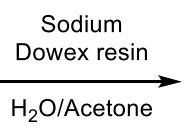<smiles>NC(=O)C1CCC2CN1C(=O)N2OS(=O)(=O)[O-]</smiles>

$( \pm)-9,94 \%$ vibactam sodium salt $11 \%$ over 16 steps

Scheme 2 First racemic synthesis of avibactam 


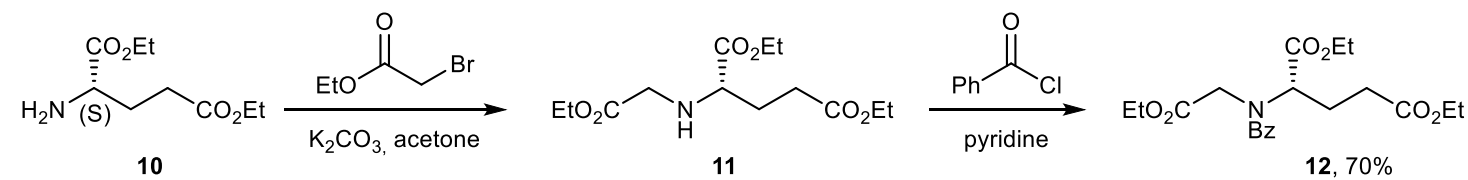

10

11

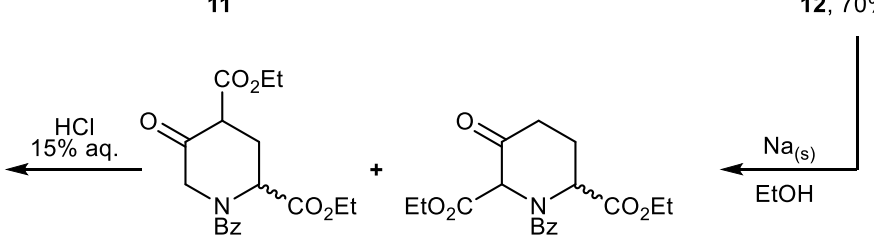

(士)-14, 85\%

$13+13 ', 75 \%$

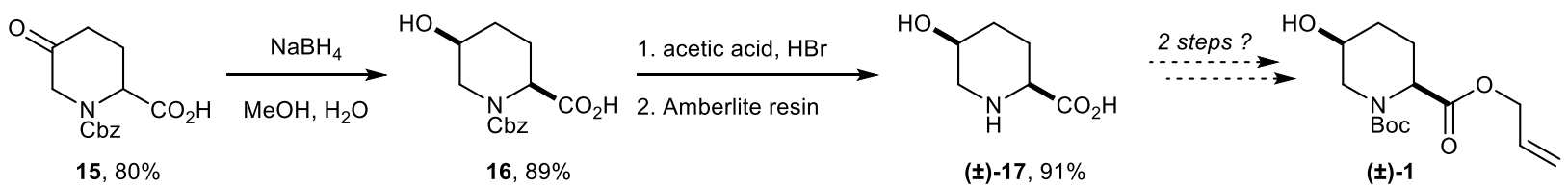

$39 \%$ over 8 steps

Scheme 3 Racemic synthesis of 5-hydroxypipecolic acid $\mathbf{1 7}$ and formation of key intermediate $\mathbf{1}$

\subsection{First improvements (Novexel).}

One major improvement brought up by Novexel chemists ${ }^{31}$ was to start the synthesis from commercially available enantiopure 2-pyrrolidone 18 . This bypassed the ten steps necessary to reach piperidine $\mathbf{1}$, thus halving the total number of steps needed to make avibactam (Scheme 4). First, $y$-lactam 18 was subjected to Corey-Chaykovsky-type reaction conditions and addition of a sulfonium ylide yielded zwitterionic enolate 19. Reaction with lithium chloride under acidic conditions gave an intermediate chloro-ketone onto which $O$-benzylhydroxylamine was condensed to furnish oxime $\mathbf{2 0}$ as an $E / Z$ mixture. The cyclization to piperidine $\mathbf{2 1}$ was accomplished by acidic treatment, also causing cleavage of the Boc group, followed by neutralization. The oxime was then reduced to an hydroxylamine that was isolated as its oxalate salt 22 as a 75:25 mixture of trans and cis isomers with a $65 \%$ overall yield. The bicyclic core was generated by treatment with triphosgene to form urea 23. A strictly controlled (temperature, reaction time, $\mathrm{pH}$ ) hydrolysis of the ester using lithium hydroxide allowed the selective saponification of the trans derivative and the isolation of solely the corresponding trans carboxylic acid. Primary amide $\mathbf{7}$ is then obtained by formation of a pivaloyl anhydride followed by treatment with ammonia. The subsequent steps are nearly identical to the ones presented in Scheme 2.

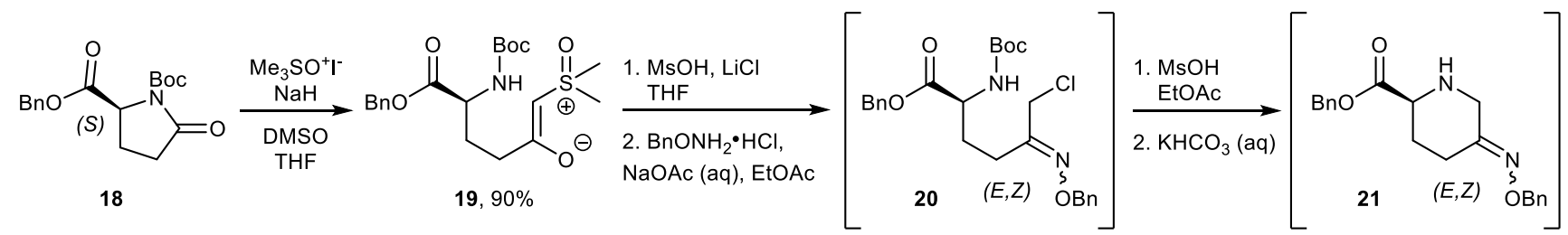<smiles>NC(=O)[C@@H]1CC[C@@H]2CN1C(=O)N2Br</smiles>

7, $35 \%$

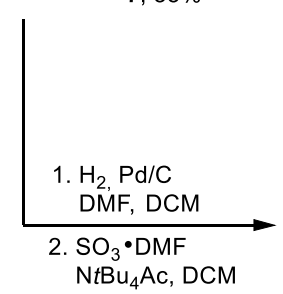

Sodium ethyl-2-hexanoate

$8,55 \%$<smiles>CC1CCC(C(=O)O)C2CN1C(=O)N2[O]</smiles>

23, $80 \%$ trans:cis $(75: 25)$

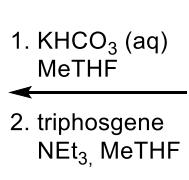

triphosgene
$\mathrm{NEt}_{3}, \mathrm{MeTHF}$

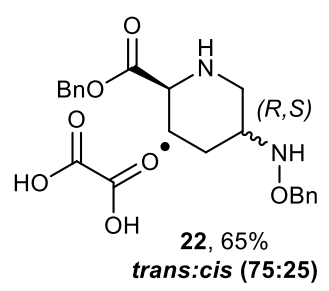

1. $\mathrm{NaBH}(\mathrm{OAc})_{3}$ $\mathrm{H}_{2} \mathrm{SO}_{4}, \mathrm{EtOAc}$

2. oxalic acid EtOAc, Acetone

Scheme 4 Second synthesis of avibactam by Novexel 

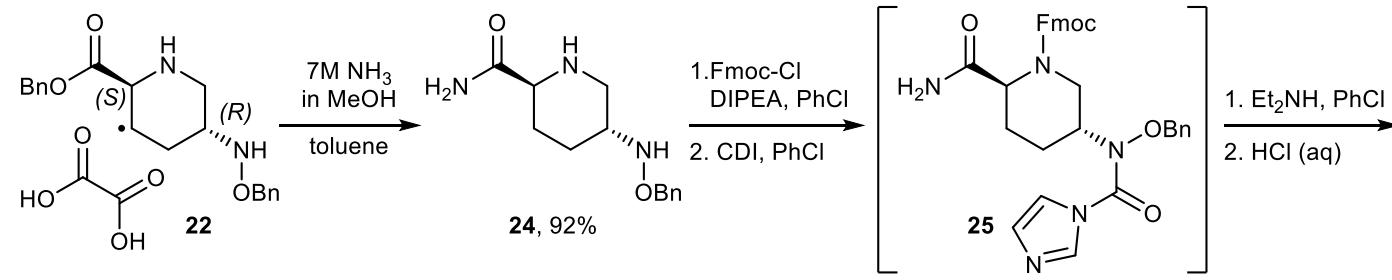

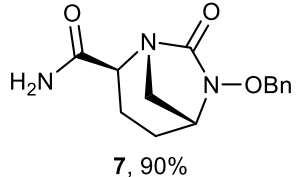

$83 \%$ overall yield

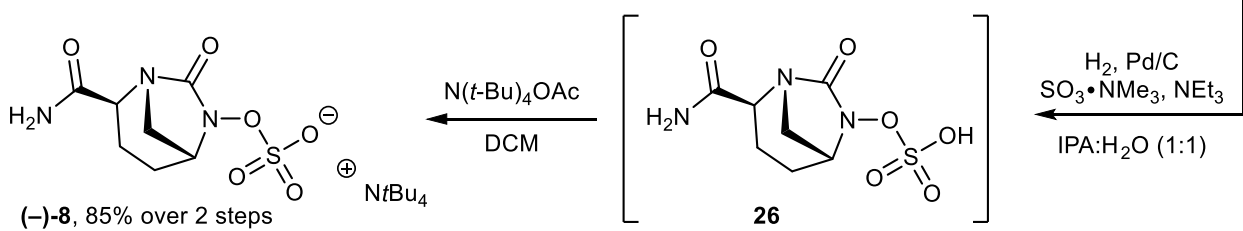

Scheme $\mathbf{5}$ Improved synthesis of bicycle $\mathbf{7}$ from trans piperidine $\mathbf{2 2}$ and of avibactam ammonium salt $\mathbf{8}$ from $\mathbf{7}$

After debenzylation by hydrogenolysis, the sulfate group was introduced and avibactam was eventually isolated as its sodium salt 9. The overall efficiency of the route was greatly improved from 26 steps to 15 steps and from less than $4 \%$ to $8 \%$. Yet, the Process Mass Intensity (PMI) was calculated at 6480 (indicating that $1 \mathrm{~kg}$ of avibactam was produced at the expense of $6480 \mathrm{~kg}$ of starting materials). As this was still not suitable for industrial purposes, further streamlining was needed. Moreover, toxic reagents or solvents such as dichloromethane and DMF or hazardous reactants such as sodium hydride should ideally be avoided and some steps ( 23 to $\mathbf{7}$ in particular) were not efficient enough.

\subsection{Subsequent improvements (AstraZeneca/Forest).}

First, three key changes were done to optimize the transformation of 18 into piperidine 22: potassium tertbutoxyde was used instead of sodium hydride; the chlorination and the formation of the oxime were performed in a one-pot fashion; only the final product $\mathbf{2 2}$ was purified. This allowed to isolate the $(S / R)$ isomer of piperidine $\mathbf{2 2}$ with a $56 \%$ overall yield on a $300 \mathrm{~kg}$ scale. ${ }^{32}$

Since only the trans isomer of $\mathbf{2 2}$ was isolated, the tedious selective saponification step could be avoided and amide $\mathbf{2 4}$ was directly obtained in $92 \%$ yield by treatment with a methanolic solution of ammonia (Scheme 5). A selective Fmocprotection of the amine was necessary before activating the hydroxylamine with carbonyldiimidazole to give intermediate 25. The deprotection of the Fmoc group, which triggers the<smiles>CCOC(=O)c1ccc(O)cn1</smiles>

27<smiles>CCCCCCC</smiles><smiles>CCOC(=O)[C@@H]1CC[C@@H](O)CN1</smiles>

28 cyclization to get bicyclic adduct 7, was achieved with diethylamine, which was crystallized after acidic treatment. The overall yield of this sequence is $83 \%$ (vs $23 \%$, see Scheme 4 ) and it avoids the use of triphosgene. The hydrogenolysis solvent was changed to a 1:1 mixture of isopropanol and water (instead of DMF/DCM), which lowered the pKa of the resulting hydroxylamine. This rendered possible a one-pot debenzylation/sulfation by carrying the hydrogenolysis in presence of triethylamine and the commercially available $\mathrm{SO}_{3} \bullet \mathrm{NMe}_{3}$ complex. The ammonium salt 8 was eventually isolated in $85 \%$ over two steps (vs $55 \%$, see Scheme 4 ).

This route only requires 5 steps with isolation and delivers avibactam sodium salt in $35 \%$ from 2-pyrrolidone 18 . The route is also safer as many toxic and/or hazardous reagents and solvent can be avoided and the PMI was diminished to 526 .

\subsection{Alternative route.}

In 2018, the teams of Chen and Wu, described an alternative approach to avibactam, starting from ethyl 5-hydroxypicolinate hydrochloride $\mathbf{2 7}$ (Scheme 6). ${ }^{33}$ This aromatic starting material is first fully reduced, thus avoiding lengthy multistep protocols, to directly obtained piperidine 28 with an excellent 97:3 diasteromeric ratio in favor of the cis isomer. Using a lipase, the $(S, S)$ ester 29 can be easily separated from the $(R, R)$ acid 29' after a protection step with a Boc group. The introduction of the hydroxylamine group was realized following Aventis protocol (see Scheme 2) to give $\mathbf{3 0}$ that was converted into primary amide $\mathbf{2 4}$ (31\% yield over 6 steps from 27).

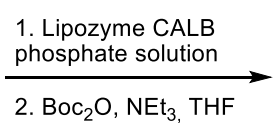

2. $\mathrm{Boc}_{2} \mathrm{O}, \mathrm{NEt}_{3}, \mathrm{THF}$

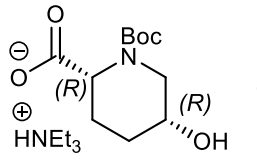

29, (water soluble)<smiles>CCOC(=O)[C@@H]1CC[C@@H](O)CN1C(=O)OC</smiles>

$29,43 \%$ $\mathrm{OH}$

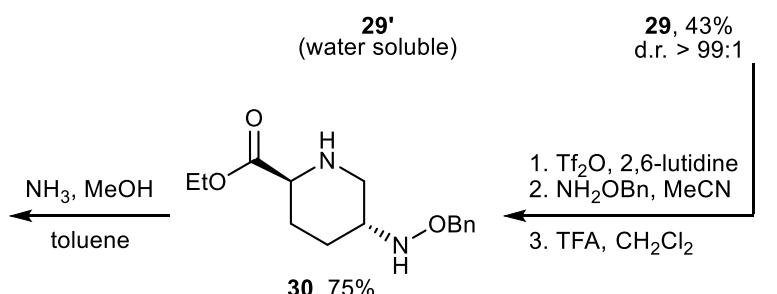

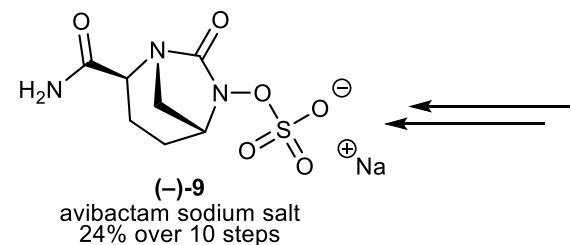<smiles>[R4][C@H]1CC[C@@H](NOCc2ccccc2)CN1</smiles>

Scheme 6 Use of lipase catalytic resolution for the synthesis of trans piperidine 24 
The rest of the synthesis is the same as the AstraZeneca/Forest route described by Golden. Avibactam sodium salt could thus be isolated with $24 \%$ yield over 10 steps on a $400 \mathrm{~g}$ scale.

\section{Synthesis of relebactam}

\subsection{History.}

Relebactam, ${ }^{34}$ initially known as MK-7655, ${ }^{16}$ was developed by Merck, taking cues from their own research program on bicyclic $\beta$-lactam BLIs ${ }^{35,36}$ and from the development of avibactam. ${ }^{37}$ It was approved by the FDA in 2019 in combination with imipenem and cilastatin (a renal dehydropeptidase inhibitor generally associated to imipenem to prevent its degradation in the kidney) under the tradename Recarbrio ${ }^{\mathrm{TM}}$. The initial "medicinal chemistry" route used bicyclic acid $\mathbf{6}$ (from the initial avibactam synthesis, see Scheme 2) as the key starting material, onto which various amines could be coupled to get a wide range of derivatives. ${ }^{37}$ Later on, a route was specifically designed to access relebactam on multikilogram scale.

\subsection{First Synthesis.}

The first specific route to synthetize relebactam ${ }^{38}$ was described in details in 2011 by the team of Mangion. ${ }^{39}$ L-Pyroglutamic acid 31 was first coupled with $\mathrm{N}$-Cbz-aminopiperidine $\mathbf{3 2}$ and then protected with a Boc group to give pyrrolidinone $\mathbf{3 3}$ with $87 \%$ yield (Scheme 7). The homologation step is analogous to Novexel second synthesis (see Scheme 4) and the addition of trimethylsulfoxonium iodide in the presence of potassium tert- butoxide gave sulfoxonium $\beta$-keto-ylide 34. Following a strategy initially developed by Baldwin, ${ }^{40}$ this zwitterion served as a carbene precursor and, in presence of an iridium complex, a N-H insertion reaction gave piperidine 35 . Reduction of the ketone with $\mathrm{LiBH}_{4}$ selectively furnished cis alcohol 36 with a 12:1 diastereomeric ratio. Activation of the alcohol by forming $p-\mathrm{CF}_{3}-$ benzenesulfonamide 37 proved crucial to favor its $S_{N} 2$ displacement by $\mathrm{N}$-Boc- $\mathrm{O}$-benzyle hydroxylamine. After acidic deprotection of both $\mathrm{N}$-Boc groups, hydroxylamine $\mathbf{3 8}$ was isolated in $58 \%$ yield by crystallization of its tosylate salt $(21 \%$ over 8 steps from 31). Cyclic $N$-oxy-urea 39 was obtained by cyclization with triphosgene in the presence of phosphoric acid. Hydrogenolysis of the $O$-benzyl group was performed with $\mathrm{Pd}(\mathrm{OH})_{2}$ in THF. Because of the concomitant cleavage of the $\mathrm{Cbz}$ group, the reaction was carried out in the presence of tertbutylcarbonate to reprotect in situ the piperidine and form $\mathrm{N}$ hydroxy-urea 40 . The sulfate group was introduced by reaction with $\mathrm{SO}_{3} \bullet$ pyridine, then ammonium salt $\mathbf{4 1}$ was isolated after treatment with tetra-tert-butylammonium hydrogenosulfate. Because relebactam is only stable in aqueous solution at $\mathrm{pH}$ between 4 and 8 , extensive optimization was needed to achieve the deprotection of the Boc group. Eventually, by using $\mathrm{HBF}_{4} \bullet \mathrm{Et}_{2} \mathrm{O}$ in 2,2,2-trifluoroethanol (TFE), the protecting group could be efficiently removed, although the need for an aqueous work-up complicated the process and only allowed the isolation of relebactam with $68 \%$ yield. The overall yield of this 13 -step synthesis is $10 \%$.

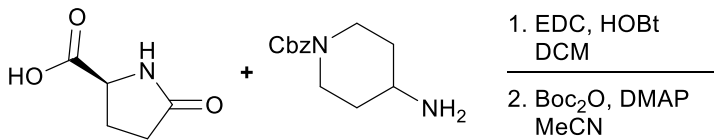

31
32

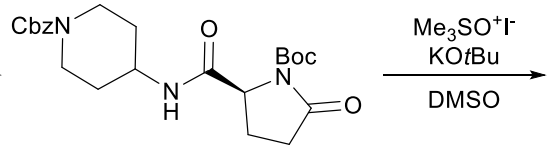

33, $87 \%$

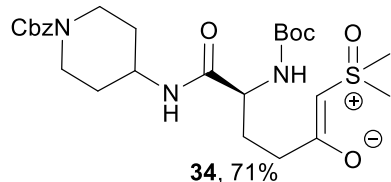

$34,71 \%$

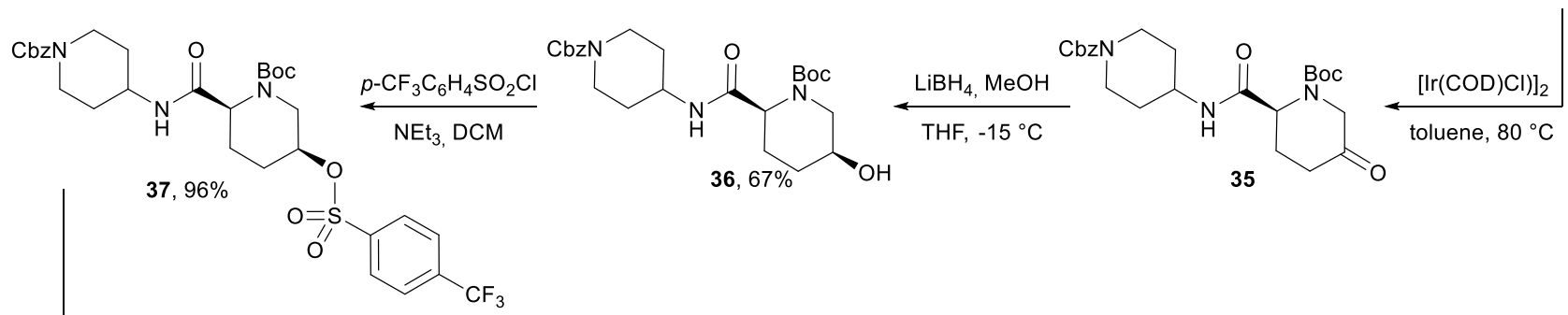

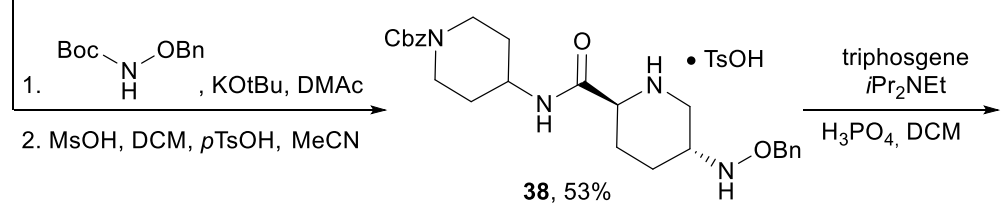<smiles>CC(C)(C)N1CCC(NC(=O)[C@@H]2CC3CN2C(=O)N3Cc2ccccc2)CC1</smiles>

$\mathrm{Pd}(\mathrm{OH})_{2}, \mathrm{Boc}_{2} \mathrm{O}$

$\mathrm{H}_{2}$, THF $39,87 \%$ ( $21 \%$ over 8 steps)
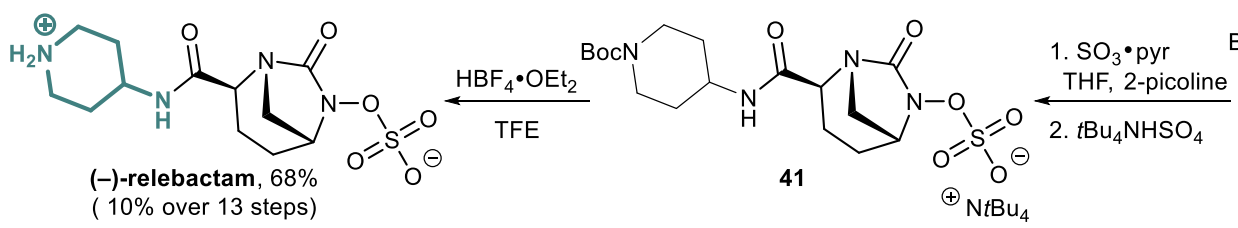<smiles>CON1C(=O)N2C[C@H]1CC[C@H]2C(=O)NC1CCN(C(=O)OC(C)(C)C)CC1</smiles>

$40,82 \%$

Scheme 7 First synthesis of relebactam 


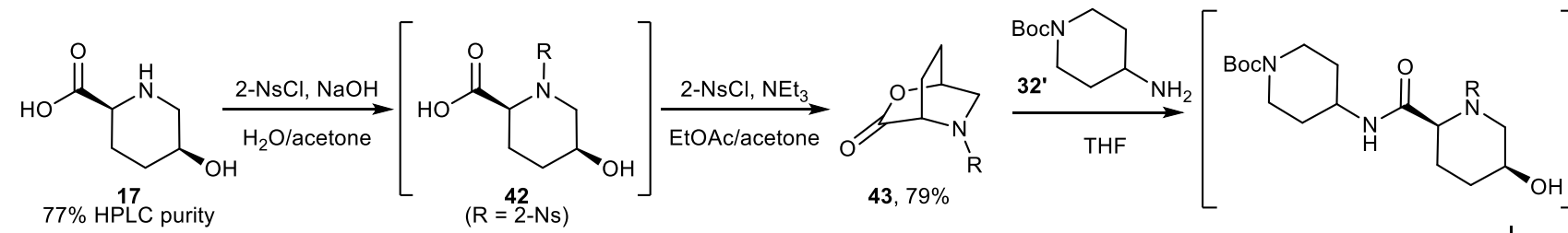

$$
\text { }
$$

46, $92 \%$

Scheme 8 Manufacturing route to relebactam

\subsection{Second synthesis.}

An improved manufacturing route was then developed and reported by the team of Miller in 2014. ${ }^{41}$ The synthetic sequence started with the protection of enantiopure amine 17, which is commercially available $(1000 \$ / \mathrm{kg})$, by a 2 nitrobenzenesulfonyl (2-Ns) group (Scheme 8 ). The 2-Ns group was also used to promote the lactonization of $\mathbf{4 2}$ into $\mathbf{4 3}$ and helped its crystallization with $99 \%$ purity (compared to the $77 \%$ purity of 17). Opening of the lactone with $\mathrm{N}$-Bocaminopiperidine 32 ', followed by nosylation of the alcohol, gave amide 44 in $98 \%$ yield. Using the lactone as a reactive intermediate prevented the use of coupling agents such as EDC and HOBt (see Scheme 7), which are expensive and generate unwanted by-products. Compound $\mathbf{4 5}$ was then obtained by substitution of the secondary nosylate by $\mathrm{N}$-Ns-O-benzylhydroxylamine, followed by cleavage of the sulfonamide using thioglycolic acid. Compared to the previous synthesis of $\mathrm{N}-\mathrm{Cbz}$ analogue 38, only 6 steps are needed instead of 8 and the overall yield is $54 \%$ instead of $21 \%$. Moreover, the change of
40, $90 \%$<smiles>[R]OC1CCC(C(=O)NC2CCN(C(C)(C)C)CC2)C([R])C1</smiles>
$44,98 \%$<smiles>CCCON[C@H]1CC[C@@H](C(=O)NC2CCN(C(=O)OCc3ccccc3)CC2)NC1</smiles>

38<smiles>O=C(O)C1CCCCN1</smiles>

$(-)-47,43 \%$

starting material precluded the homologation step and therefore the use of the expensive iridium catalyst, which brought about extensive purification steps to reach pharmaceutically acceptable levels of metal traces in the final compound. Formation of urea $\mathbf{4 6}$ was achieved with triphosgene with $92 \%$ yield and the hydrogenolysis of the $O-B n$ group was more straightforward, as the problematic $\mathrm{Cbz}$ group was no longer used. Nevertheless, when carried out at pilotscale this hydrogenolysis step proved somewhat problematic and further refinements of this key step were recently disclosed. The more recent protocol uses DABCO as a catalyst and relies on an in situ $O$-silylation followed by deprotection and recrystallization to isolate $\mathbf{4 0 .}{ }^{42}$ Eventually, it was demonstrated that the final deprotection of the Boc group to access relebactam could be achieved in a much more efficient manner using trimethylsilyliodide. This second route is thus only 11-step long and its overall yield is $42 \%$. In 2019, an alternative approach to 45 using a $\mathrm{FeCl}_{3} \cdot 6 \mathrm{H}_{2} \mathrm{O} / \mathrm{NaBH}_{4}$ diasteroselective reduction of an oxime precursor was reported by researchers from Merck. 43

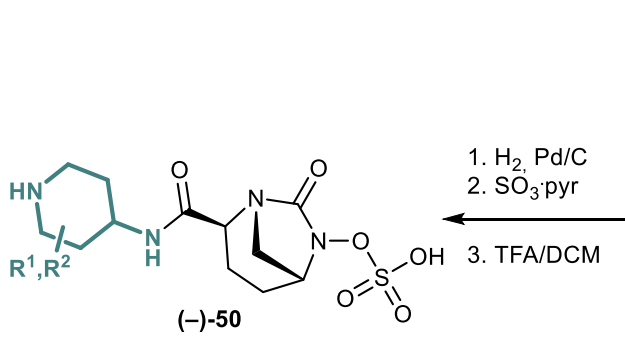

$(-)-50$

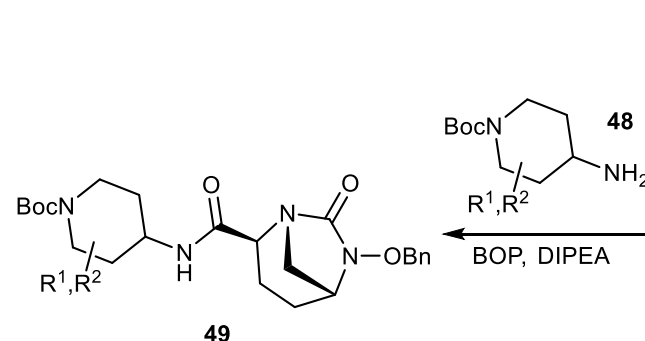

49

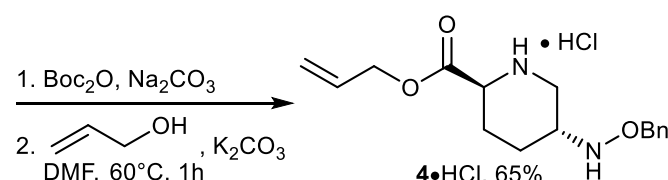

DMF, $60^{\circ} \mathrm{C}, 1 \mathrm{~h}$ $4 \cdot \mathrm{HCl}, 65 \%$

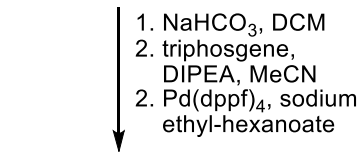<smiles>O=C(O)[C@@H]1CC[C@@H]2CN1C(=O)N2Cc1ccccc1</smiles>

$(-)-6,90 \%$ $(56 \%$ over 6 steps

Scheme 9 Synthesis of key acid intermediates $\mathbf{4 7}$ and $\mathbf{6}$ from a relebactam precursor. 


\section{Synthesis of other DBOs using the relebactam route}

5.1 Diverging route from a common intermediate.

Another team of chemist from Merck recently disclosed the synthesis of relebactam analogues from advanced intermediate prepared according to Mangion's synthetic route. ${ }^{44}$ Starting from amide 38 (then available in $\mathrm{kg}$ scale at Merck), an enzymatic cleavage using Amano protease P6 led to carboxylic acid 47 (Scheme 9). Then, $\mathrm{N}$ - and $\mathrm{O}$-protections, followed by acidification allowed the isolation of the hydrochloride salt of ester 4 in $65 \%$ yield. Following the initial route for the synthesis of avibactam (see Scheme 2), bicyclic carboxyclic acid 6 was prepared in $90 \%$ yield. From there (or eventually from acid 47 ), coupling with substituted piperidines $\mathbf{4 8}$ would give amide $\mathbf{4 9}$ which could then be turned into a relebactam analogues $\mathbf{5 0}$, after the standard hydrogenolysis/sulfatation/deprotection sequence. Only the preparation of a mono-fluoro analogue was described in this report. Overall, the sequence is relatively long to bring very minor changes to the structure of relebactam.

\subsection{Synthesis of triazole analogues.}

The route described by Mangion ${ }^{39}$ served as the basis for a study by the groups of Ethève-Quelquejeu and Arthur. ${ }^{45}$ Starting from N-Boc-methyle-(S)-5-oxopyrrolidine-2carboxylate 51, the key piperidine $\mathbf{5 2}$ was obtained in 6 steps and $27 \%$ overall yield (Scheme 10). The 6-step sequence included the sulfonium homologation followed by the Ircatalyzed cyclization, the reduction of the resulting ketone (see Scheme 7) and the hydroxylamine was installed using a Mistunobu reaction with $\mathrm{N}$-Nosyl-O-benzyl hydroxylamine, then both nitrogens were deprotected. The ester moiety was reduced to the corresponding primary alcohol, which was protected as a silyl ether before the triphosgene cyclization to give 53 with $25 \%$ yield. The TBS ether was converted into a primary azide in three steps to give $\mathbf{5 4}$ that was subjected to Huisgen [3+2] cycloaddition with 3-ethynylpyridine or trimethylsilyl acetylene to give 55a and 55b in $77 \%$ and $99 \%$ yield, respectively. The corresponding sodium sulfate derivatives $\mathbf{5 6 a}$ and $\mathbf{5 6} \mathrm{b}$ were then isolated with moderate yields in three steps. Preliminary studies showed that these derivatives, despite being moderate BLIs, could potentiate the activity of amoxicillin against mycobacteria, which could be attributed to inhibition of the L,D-transpeptidases by the DBOs.

\section{Synthesis of DBOs with variations of the amide group}

Following the advent of avibactam and relebactam, several companies started research programs to develop their own DBO BLIs. Most of those only differ at the carbonyl moiety and incorporate a hydrazide or an $\mathrm{N}$-alkoxy-amide instead of an amide. Their synthesis is largely based on those previously disclosed, yet the best compounds display significant activities and are currently undergoing clinical phases.

\subsection{Nacubactam and other FPI compounds}

Nacubactam (previously known as, FPI-1459, OP0595 and RG6080), was initially discovered simultaneously by Meiji Seika Pharma ${ }^{46}$ and Fedora Pharmaceuticals (initially as NAEJA Pharmaceuticals), ${ }^{47}$ which formed a joint venture for its development in association with Roche (Roche acquired worldwide rights to nacubactam, except in Japan). Nacubactam has been undergoing clinical trials in association with meropenem (a carbapenem antibiotic). Like avibactam, nacubactam has inhibitory properties against class $A$ and $C \beta$ lactamases. However, contrary to avibactam, nacubactam also exhibits an intrinsic antibacterial activity, by inhibiting penicillinbinding-protein-2 (PBP2), and an enhancer effect, which makes it promising against MBL-producing bacteria. ${ }^{48,49}$ Nacubactam was prepared from carboxylic acid 6 by coupling with tert-butyl (2-(aminooxy)ethyl)carbamate to give the corresponding amide 57 with $84 \%-89 \%$ yield (Scheme 11). ${ }^{46,47}$ Subsequent elaboration of the sulfate moiety and deprotection of the Boc group led to nacubactam in 4 steps. Various alkoxy-amides and hydrazides, prepared following the same protocol (FPI-1465, FPI-1523 and FPI-1602), were also found to possess inhibitory properties against both SBLs (of classes A and D) and PBP2. ${ }^{25}$

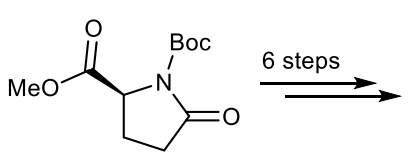

51<smiles>[R]c1cn(C[C@@H]2CC[C@@H]3CN2C(=O)N3OS(=O)(=O)[O-])nn1</smiles>

56a, 10\%, R=-\{- $-56 \mathrm{~b}, 9 \%, \mathrm{R}=\mathrm{SiMe}_{3}$

$(-)-\mathbf{5 6 b}, 9 \%, \mathrm{R}=\mathrm{SiMe}_{3}$
$(0.3 \%$ over 16 steps $)$

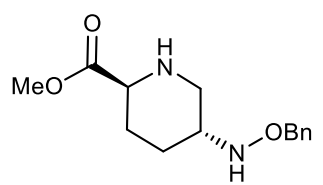

$52,27 \%$

1. $\mathrm{H}_{2}, \mathrm{Pd} / \mathrm{C}, \mathrm{MeOH}$ 2. $\mathrm{SO}_{3}$.pyr, pyridine

3. Dowex resin $\mathrm{Na}^{+}$
1. $\mathrm{LiBH}_{4}, \mathrm{THF}, 0^{\circ} \mathrm{C}$

2. TBSCl, DCM

3. triphosgene, DIPEA $\mathrm{MeCN}, 0^{\circ} \mathrm{C}$

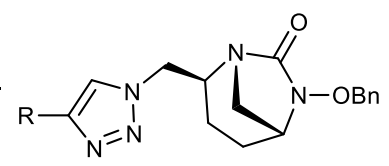

55a, $77 \%, \mathrm{R}=-\{\}$

55b, $99 \%, \mathrm{R}=\mathrm{SiMe}_{3}$
1.TBAF, THF, $0^{\circ} \mathrm{C}$

2. $\mathrm{MsCl}, \mathrm{NEt}_{3}$

DMAP, DCM, $0^{\circ} \mathrm{C}$

3. $\mathrm{NaN}_{3}$

DMF, $80^{\circ} \mathrm{C}$

53, $25 \%$

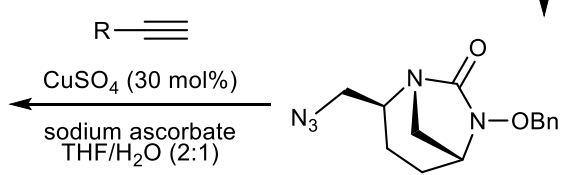

(-) $-54,56 \%$

Scheme 10 Synthesis of triazole analogues of relebactams 
<smiles>CCCCON1C(=O)N2CC1CCC2C(=O)O</smiles>

$(-)-6$ 1. $\mathrm{NEt}_{3}, \mathrm{DCM}, \mathrm{PivC}$ 2. ammonia aq<smiles>NC(=O)C1CC2CCN1C(=O)N2OCc1ccccc1</smiles>

7, $40 \%$ $\left(\mathrm{CF}_{3} \mathrm{CO}\right)_{2} \mathrm{O}$ $\mathrm{NEt}_{3, \mathrm{DCM}}$<smiles>N#C[C@@H]1CC[C@@H]2CN1C(=O)N2Cc1ccccc1</smiles>

58, $74 \%$<smiles>C=C[C@H]1CC[C@@H]2CN1C(=O)N2OS(=O)(=O)O</smiles>

WK 4234<smiles>[R]NC(=O)[C@@H]1CC[C@@H]2CN1C(=O)N2OCc1ccco1</smiles>
57<smiles>[Te]C=[Te]</smiles><smiles>[R]NC(=O)C1CCC2CN1C(=O)N2OS(=O)(=O)O</smiles><smiles>[R][NH2+]CCO[Te]</smiles><smiles>CC(C)(C)P=PI=COC1CCNC1</smiles>
, FPI-1523 , FPI-1602

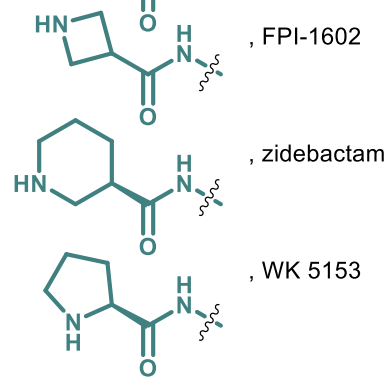

Scheme 11 Synthesis of nacubactam, zidebactam and other FPI and WK analogues.

\subsection{Zidebactam and congeners}

Zidebactam ${ }^{50}$ (previously known as WCK 5107) and its pyrrolidine analogue WK515351 were developed by Wokhardt using the same strategy as for nacubactam, starting from carboxylic acid $\mathbf{6}$ (Scheme 11). Zidebactam is undergoing clinical trials in combination with cefepime. Additionally, a nitrile analogue of avibactam was also developed: WK 4234. It was obtained from nitrile $\mathbf{5 8}$, which stemmed from primary amide $\mathbf{7}$ by trifluoroacetic anhydride-mediated dehydration $(74 \%$ yield).52 The latter was demonstrated to be particularly promising as it could not only inhibit SBLs of classes $A$ and $C$ but also oxacillinases of class $D$, including carbapenemases such as OXA-48. ${ }^{52}$

\section{Synthesis of DBOs with substituents of the carbon scaffold}

\subsection{Synthesis of NXL-105.}

The first DBO derivatives that bore various substituents on the bicyclic framework were synthetized by Novexel. One of them, NXL-105, displayed not only a BLI profile but also antibiotic properties against $P$. aeruginosa, presumably by inhibiting PBPs. ${ }^{53}$ The synthesis of this tricyclic DBO, with a fused pyrazole, required twenty steps from 3,5-dioxopiperidine 59 (Scheme 12). First, Knœvenagel condensation with dimethylformamide acetal gave 60, which underwent further condensation with methyl-hydrazine to form the pyrazole ring and give 61 in $83 \%$ yield. The ketone was then reduced and the carboxyl moiety installed by a $t$-BuLi deprotonation followed by carbon dioxide addition to furnish 62 (89\%). Methylation of the acid was achieved with diazomethane and mesylation followed by hydroxylamine addition gave $\mathbf{6 3}$ in 59\% yield. Deprotection of the Boc group followed by basic treatment set the stage for the formation of the bicyclic core using diphosgene and $\mathbf{6 4}$ was isolated in good yield after treatment with tartaric acid then DBU. The ester group was then reduced and the resulting primary alcohol converted into a mesylate before being substituted with $\mathrm{NaN}_{3}$ to give azide 65. The azide was then reacted with triphenylphosphine following by treatment with methyliodide to give a phosphonium iodide that was converted to methylamine $\mathbf{6 6}$ by heating in an aqueous sodium carbonate solution. From this point, the formation of sulfate $\mathbf{6 7}$ and the final isolation of NXL-105 as a sodium salt followed the "usual" route, plus additional protection/deprotection steps of the amine. The synthesis of NXL-105 is rather long ( 20 steps) and no details are provided concerning the obtention of a racemic mixture or a single enantiomer (and if so, how the resolution was carried out). Very recently, Entasis Therapeutics (a spin-out from AstraZeneca) patented novel pyrazolo-DBOs using an updated version of the NXL-105 route to access 64 , which is then transformed into an amidine-type moiety. ${ }^{54}$

\subsection{Synthesis of IID572.}

IID572 is another type of tricyclic DBO that incorporates a pyrrolidone ring, which replaces the amide functional group, and that was developed by Novartis. ${ }^{55,56} \mathrm{~A}$ late-functionalization strategy was implemented starting from bicyclic acid 6 that was first esterified (Scheme 13). The conjugated double bond was then installed by an $\alpha$-selenation/oxidation/elimination sequence to give 69 with $21 \%$ yield over three steps. After disappointing results using a conventional Michael addition reaction the methyleneamine moiety was incorporated through a Giese addition using an Ir-catalyzed UV-light photoredox process to generate the primary radical intermediate. ${ }^{57}$ Compound $\mathbf{7 0}$ was obtained with a good $79 \%$ yield, yet only $10 \%$ of the desired diastereoisomer were isolated. Acidic cleavage of the Boc group set the stage for the lactamisation under basic condition to give 71, which was then converted into IID572 in four steps. This synthesis showcases how modifications of the carbon skeleton can be tedious, as IID572 was obtained with only $0.1 \%$ yield in 9 steps. IID572 did not possess any intrinsic antibiotic effect but exhibited a broad anti-SBL spectrum and could restore susceptibility to piperacillin in some piperacillintazobactam resistant clinical strains. ${ }^{56}$

\subsection{Cyclopropane-fused DBO.}

In 2014, the team of Durand-Réville at AstraZeneca reported the synthesis and evaluation of tricyclic DBOs bearing a fused cyclopropyl ring. ${ }^{58}$ The hypothesis was that increasing the overall ring strain in the DBO scaffold could potentially improve the inhibition spectrum of the molecules. However, the formation of this strained ring required that the key enantioenriched monocyclic intermediate would no longer be a piperidine but a tetrahydropyridine, with a double bond suitable poised for a cyclopropanation reaction. 


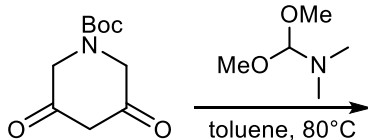

59<smiles>CCOC(C)NNCC(=O)OCCN</smiles>

1. $\mathrm{LiBH}_{4}, \mathrm{THF} / \mathrm{MeOH}$<smiles>Cn1ncc2c1C1CC(C2CN)N(OCc2ccccc2)C1=O</smiles>
2. $\mathrm{MsCl}, \mathrm{NEt}_{3}, \mathrm{DCM}$ 3. $\mathrm{NaN}_{3}, \mathrm{DMF}, 65^{\circ} \mathrm{C}$

$65,64 \%$<smiles>COC(=O)C1c2c(cnn2C)C2CC1N(O)C2=O</smiles>
$64,76 \%$<smiles>Cn1ncc2c1CN(C(=O)OCc1ccccc1)CC2=O</smiles>

$61,83 \%$<smiles>Cn1ncc2c1C(O)C[Nb]2CC(=O)O</smiles>

$62,89 \%$ 1. $\mathrm{CH}_{2} \mathrm{~N}_{2}, \mathrm{DCM}$ 2. $\mathrm{MsCl}, \mathrm{NEt}_{3}, \mathrm{DCM}$ 3. $\mathrm{H}_{2} \mathrm{NOBn}, \mathrm{NaOH}$ $\checkmark \mathrm{DCM} / \mathrm{H}_{2} \mathrm{O}$

1. $\mathrm{HCl}$, Dioxane,
then $\mathrm{NH}_{3} 20 \%$ aq.
$\begin{aligned} & \text { 2. diphosgene, } \mathrm{NEt}_{3}, \mathrm{MeCN} \\ & \text { 3. tartric acid, then } \mathrm{DBU}\end{aligned}$<smiles>COC(=O)[C@@H]1c2c(cnn2C)[C@@H](NOCc2ccccc2)CN1C(=O)OCc1ccccc1</smiles>

(士)-63, 59\%

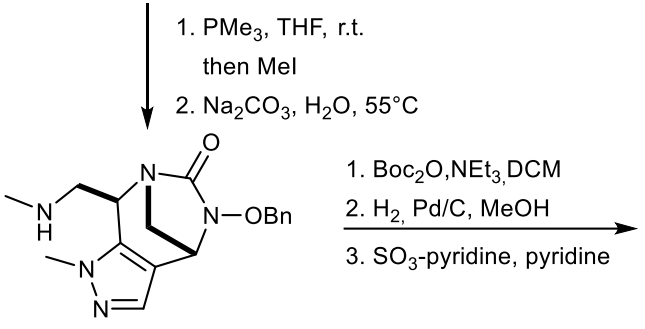

66, $27 \%$<smiles>CNCC1c2c(cnn2C)C2CC1N(OS(=O)(=O)[O-])C(=O)N2CC(C)(F)F</smiles>

67, $60 \%$

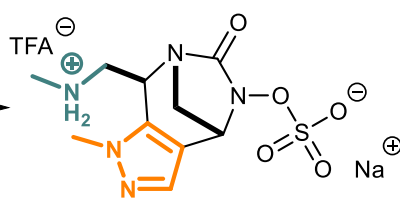

( \pm )-NXL-105, quant.

Scheme 12 Racemic synthesis of NXL-105

This led to a complete redesign of the synthetic route. The key enantioselective step was a dynamic kinetic asymmetric transformation (DYKAT) developed by the group of Trost. ${ }^{59}$ Asymetric Pd-catalyzed opening of vinyl epoxide $\mathbf{7 2}$ with phthalimide gave allylamine $\mathbf{7 3}$ in near perfect yield and enantioselectivity ( $94 \%$ yield and $95 \%$ ee) on up to a $100 \mathrm{~g}$ scale (Scheme 14). The alcohol group was then protected as TBS ether and the phthalimide cleaved to give primary amine $\mathbf{7 4}$, which was alkylated and Boc-protected to furnish Weinreb amide $\mathbf{7 5}$. Addition of propenylmagnesium bromide (which was found to fare better than vinyl magnesium bromide in both the alkylation and the ring forming steps) led to ketone $\mathbf{7 6}$, which was submitted to Hoveyda-Grubbs catalyst to promote a ringclosing metathesis and give key unsaturated monocyclic precursor 77 in 7 steps and $36 \%$ overall yield. From there, a stereoselective Luche reduction gave cis-allylic alcohol $\mathbf{7 8}$, which was subjected to a directed Simmons-Smith cyclopropanation, yielding cis-cyclopropyl-fused piperidine $\mathbf{7 9}$ ( $50 \%$ over 2 steps). The hydroxylamine moiety was added by a Mitsunobu reaction (80), then the Boc group was selectively removed using TBSOTf (thus keeping the alcohol protected) followed by cleavage of the dinitro-sulfonylamide to give $\mathbf{8 1}$. The tricyclic scaffold was formed by triphosgene cyclization and the primary alcohol was elaborated into a primary amide in three steps (deprotection/oxidation/amination) to give $\mathbf{8 3}$. Finally, the usual 3-step sequence yielded $\mathbf{8 4 a}$ as a sodium salt, which represents a 19 steps synthetic effort with a combined yield of $1.8 \%$. The other diasteroisomer $\mathbf{8 4 b}$ was also obtained in 12 steps from $\mathbf{7 7}$ by performing the cyclopropanation (CoreyChaikovsky) before the deprotection of the allylic alcohol.<smiles>CCCCON1C(=O)N2C[C@H]1CC[C@H]2C(=O)O</smiles>

$(-)-6$

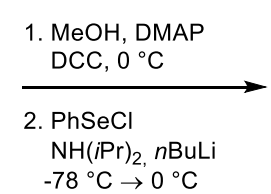

$-78^{\circ} \mathrm{C} \rightarrow 0^{\circ} \mathrm{C}$

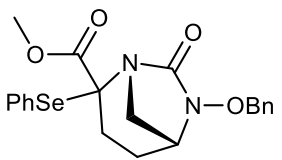

68

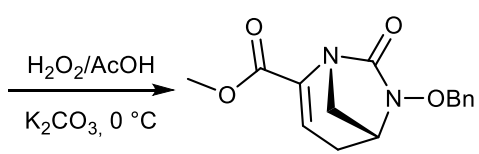

$69,21 \%$ $\frac{\text { [lr] } 2 \times 0.5 \mathrm{~mol} \%}{7 \mathrm{~d}, \mathrm{hv}(8 \mathrm{~W}, \text { UVA) }}$

$[\mathrm{Ir}]=$

$\operatorname{Ir}\left[\mathrm{df}\left(\mathrm{CF}_{3}\right) \mathrm{ppy}_{2}(\mathrm{dtbpy})\right] \mathrm{PF}_{6}$

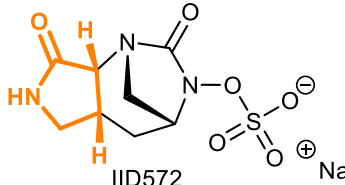

( $0.1 \%$ over 9 steps)

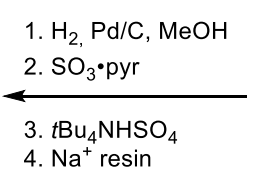

4. $\mathrm{Na}^{+}$resin

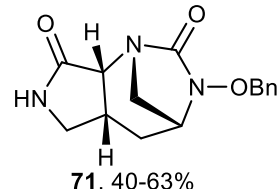

$71,40-63 \%$
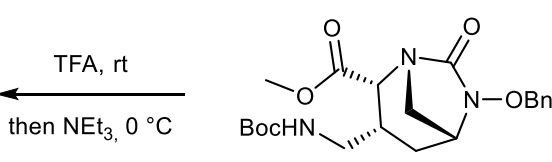

$70,10 \%$

(+ 3 diastereoisomers, $69 \%$ )

Scheme 13 Synthesis of IID572 


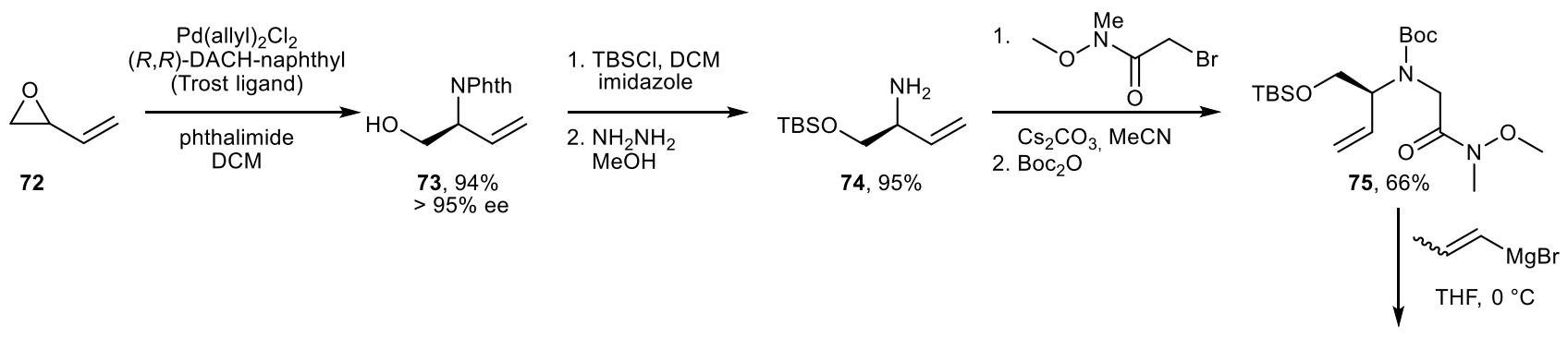

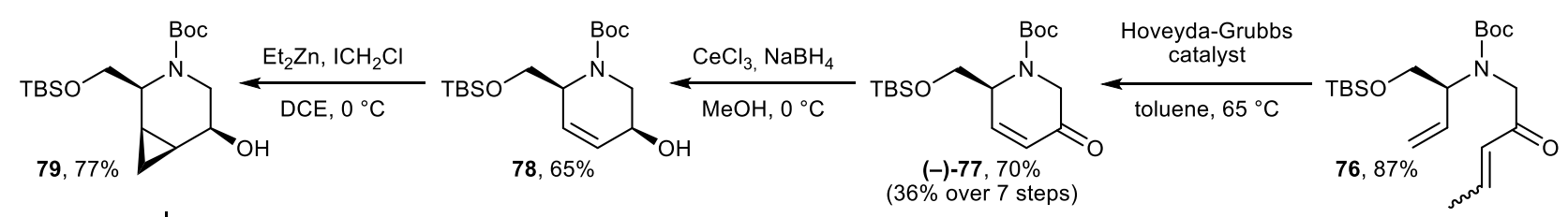
$\mathrm{BnO}_{\mathrm{N}^{\mathrm{N}}}-\mathrm{DNs} \mid \begin{aligned} & \mathrm{PPh}_{3}, \mathrm{DIAD} \\ & \text { toluene }\end{aligned}$

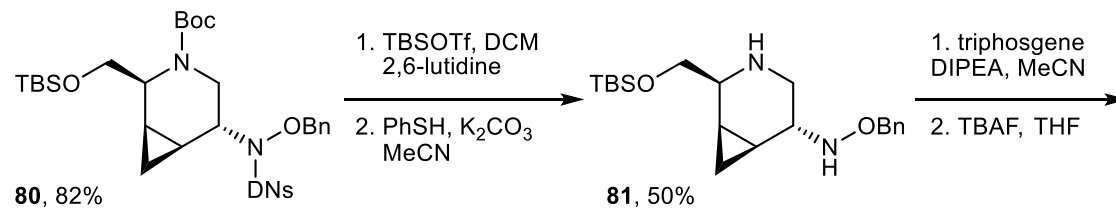<smiles>CC(C)O[14C](=O)[O-]</smiles>

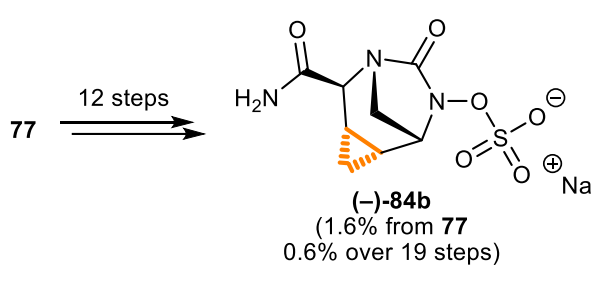

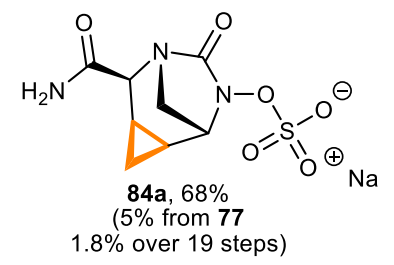

1. $10 \% \mathrm{Pd} / \mathrm{C}, \mathrm{H}_{2}, \mathrm{MeOH}$ 2. $\mathrm{SO}_{3}$ pyr, pyridine

3. $\mathrm{Na}^{+}$resin

$1.8 \%$ over 19 steps)
Scheme 14 Synthesis of cyclopropane-fused DBO

The rest of the sequence is essentially similar, albeit less efficient $(0.6 \%$ combined yield). Both compounds showed moderate to good inhibitory properties against SBLs of classes $A, C$ and $D$ and $\mathbf{8 4 b}$ displayed excellent aqueous stability.

\subsection{ETX2514 and analogues.}

In 2017, the team of Durand-Réville (now part of Entasis after the company sprung from AstraZeneca) reported the synthesis and evaluation of unsaturated analogues of avibactam, out of which ETX2514 was found to be the lead compound. As of 2019, ETX2514, now called Durlobactam, has successfully passed phase 1 and 2 of clinical trials in association with sulbactam for the treatment of resistant $A$. baumanii caused infections and was awarded Fast Track status by the FDA as a Qualified Infectious Disease Product (QIDP). All these compounds could be accessed thanks to the original route that was previously developed starting with the DYKAT reaction to access the cyclopropyl derivatives $\mathbf{8 4}$. From Weinreb amide 75, addition of prop-1-en-2-ylmagnesium bromide, followed by ring closing metathesis gave tetrahydropyridine 85 possessing a methyl group at the 4-position in $59 \%$ yield (Scheme 15).

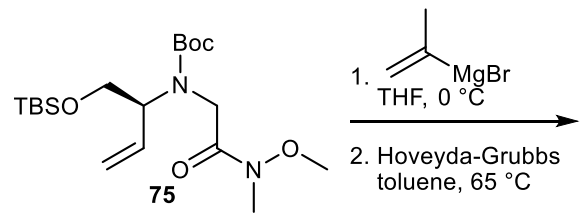

Scheme 15 Synthesis of 4-methyl unsaturated DBOs

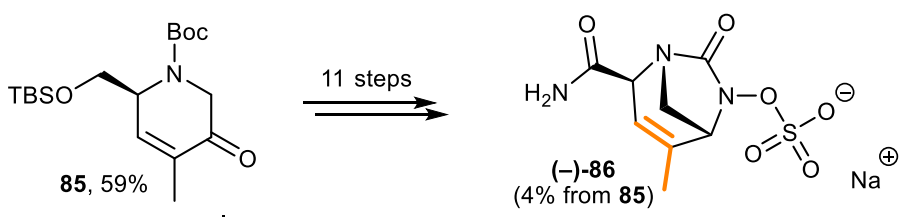<smiles>CC1=C[C@@H](C#N)N2CC(=O)N(OS(=O)(=O)[O-])C1C2</smiles> 


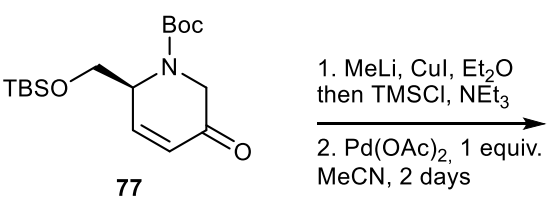

77

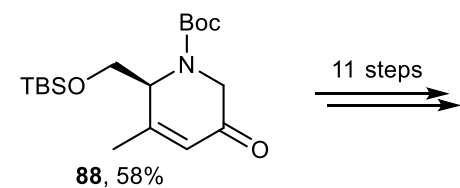

$88,58 \%$

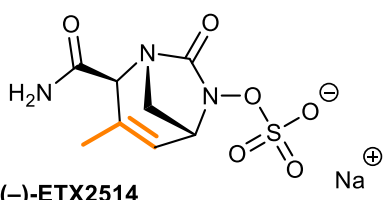

(-)-ETX251

$(1.8 \%$ from 88$)$

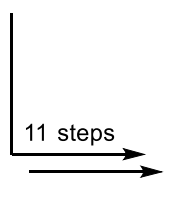

Scheme 16 Synthesis of ETX2514 and its relebactam-type analogue

Using essentially the same sequence described in Scheme 14 (the hydroxylamine was introduced with an allyl instead of a benzyl protecting group), the 4-methyl unsaturated avibactam analogue 86 was obtained in 11 steps (4\% combined yield). From 85, nitrile derivative 87 (resembling WK 4234, see Scheme 10 ) could also be obtained in 12 steps ( $2.2 \%$ overall yield). In this case, the nitrile group was formed by dehydration of the corresponding amide using Burgess reagent. The starting point to access the 3-methyl regioisomer ETX2514 was compound 77 (Scheme 16). Conjugate addition of lithium dimethylcopper was followed by trapping with chlorotrimethylsilane to access the corresponding silyl enol ether, that was subjected to a Saegusa type oxidation with a stoichiometric amount of $\mathrm{Pd}(\mathrm{OAc})_{2}$ to regenerate the double bond and form 88 (58\%). An eleven-step sequence was the necessary to synthetize ETX2514 or its relebactam-type analogue $\mathbf{8 9}$. All the compounds described in this study are obtained through a non-optimized medicinal chemistry route, with some steps being rather low yielding as well as using expensive reagents (in addition to the Saegusa oxidation, the deprotection of the allyl protecting group is also carried out with a stoichiometric amount of a palladium complex). Nevertheless, compound $\mathbf{8 6}$ and ETX2514, displayed improved activity against SBLs of classes A, C and D, with respective $\mathrm{IC}_{50}$ S of 5 and $4 \mathrm{nM}$ vs. KPC-2, 76 and $14 \mathrm{nM}$ vs. AmpC and 36 and 19 nM vs. OXA-24 (compared to $17 \mathrm{nM}, 54 \mathrm{nM}$ and $16 \mu \mathrm{M}$ for avibactam against those three enzymes). ETX2514 was found to be the most promising compound, that could restore the activity of several antibiotics against various strains of Gram-negative bacteria and substantial PBP2 inhibition in $E$. coli and $A$. baumanii.

\section{Conclusions}

Since the development of avibactam as a potent $\beta$-lactam inhibitor many DBOs were successfully developed, two of them (avibactam and relebactam) being on the market and several other being at various stages of clinical trials. Considering the dire situation caused by the emergence of multiresistant bacteria, they represent a tremendous hope in the fight against "superbugs". These various synthetic endeavors were mainly taken upon by therapeutic companies with relatively low input from academic groups. While many improvements in terms of scope and efficiency could be gained from relatively minor structural changes (nature of the amide group and substitution of the carbon framework), these changes often entailed long and complex synthetic sequences, as evidenced by the synthesis of ETX2514. One synthetic bottleneck is the formation of the cyclic $\mathrm{N}$-oxyurea as in all cases the formation of the highly constrained bicyclic scaffold is achieved from an aminopiperidine using a highly toxic triphosgene or diphosgene reagent (except in the industrial route to avibactam). Despite the importance of this key motif, alternative cyclization methods remain scarce, ${ }^{60-64}$ which might curb the development of a broader range of DBO analogues. Indeed, despite the great superiority of this family of BLI compared to $\beta$-lactam-based BLIs such as clavulanic acid or tazobactam, some unmet challenges remain for the design of even better compounds. Although DBOs can now act against all types of SBLs, none so far was found to be able to inhibit MBLs, although the combination of avibactam with aztreonam (currently in Phase III) is highly promising. Moreover, the interesting PBP2 properties of these molecules will presumably be further exploited to give birth to full-fledged antibiotics. Overall, in little more than 20 years, in parallel with the emergence of worrisome resistances in bacteria, the DBOs family has steadily grown to become an irreplaceable class of molecules that seem able to preserve our current antimicrobial arsenal and more molecules and new combinations will likely hit the market soon.

\section{Conflicts of interest}

There are no conflicts to declare.

\section{Acknowledgements}

The authors acknowledge the support of the CNRS. L.P. thanks MESRI (Paris-Saclay University) for a Ph.D. fellowship. K. C. thanks Dr Bogdan lorga (ICSN) for helpful discussions.

\section{Notes and references}

1 A. L. Demain and S. Sanchez, J. Antibiot. (Tokyo), 2009, 62, 5-16.

$2 \mathrm{~J}$. O'Neill, Tackling drug-resistant infections globally: final report and recommendations., 2016.

3 A. E. Clatworthy, E. Pierson and D. T. Hung, Nat. Chem. Biol., 2007, 3, 541-548. 
4 G. G. Zhanel, A. R. Golden, S. Zelenitsky, K. Wiebe, C. K. Lawrence, H. J. Adam, T. Idowu, R. Domalaon, F. Schweizer, M. A. Zhanel, P. R. S. Lagacé-Wiens, A. J. Walkty, A. Noreddin, J. P. Lynch III and J. A. Karlowsky, Drugs, 2019, 79, 271-289.

5 N. Kohira, J. West, A. Ito, T. Ito-Horiyama, R. Nakamura, T. Sato, S. Rittenhouse, M. Tsuji and Y. Yamano, Antimicrob. Agents Chemother., 2016, 60, 729-734.

6 M. G. P. Page, C. Dantier and E. Desarbre, Antimicrob. Agents Chemother., 2010, 54, 2291-2302.

7 S. Agnello, M. Brand, M. F. Chellat, S. Gazzola and R. Riedl, Angew. Chem. Int. Ed., 2019, 58, 3300-3345.

8 C. González-Bello, D. Rodríguez, M. Pernas, Á. Rodríguez and E. Colchón, J. Med. Chem., DOI:10.1021/acs.jmedchem.9b01279.

9 S. M. Drawz, K. M. Papp-Wallace and R. A. Bonomo, Antimicrob. Agents Chemother., 2014, 58, 1835-1846.

10 K. Coleman, Curr. Opin. Microbiol., 2011, 14, 550-555.

11 D. E. Ehmann, H. Jahić, P. L. Ross, R.-F. Gu, J. Hu, G. Kern, G. K. Walkup and S. L. Fisher, Proc. Natl. Acad. Sci., 2012, 109, 1166311668.

12 D. Y. Wang, M. I. Abboud, M. S. Markoulides, J. Brem and C. J. Schofield, Future Med. Chem., 2016, 8, 1063-1084.

13 S. J. Hecker, K. R. Reddy, M. Totrov, G. C. Hirst, O. Lomovskaya, D. C. Griffith, P. King, R. Tsivkovski, D. Sun, M. Sabet, Z. Tarazi, M. C. Clifton, K. Atkins, A. Raymond, K. T. Potts, J. Abendroth, S. H. Boyer, J. S. Loutit, E. E. Morgan, S. Durso and M. N. Dudley, J. Med. Chem., 2015, 58, 3682-3692.

14 D. M. Livermore, S. Mushtaq, M. Warner, A. Vickers and N. Woodford, J. Antimicrob. Chemother., 2017, 72, 1373-1385.

15 T. F. Durand-Réville, S. Guler, J. Comita-Prevoir, B. Chen, N. Bifulco, H. Huynh, S. Lahiri, A. B. Shapiro, S. M. McLeod, N. M. Carter, S. H. Moussa, C. Velez-Vega, N. B. Olivier, R. McLaughlin, N. Gao, J. Thresher, T. Palmer, B. Andrews, R. A. Giacobbe, J. V. Newman, D. E. Ehmann, B. de Jonge, J. O'Donnell, J. P. Mueller, R. A. Tommasi and A. A. Miller, Nat. Microbiol., 2017, 2, 17104.

16 E. B. Hirsch, K. R. Ledesma, K.-T. Chang, M. S. Schwartz, M. R. Motyl and V. H. Tam, Antimicrob. Agents Chemother., 2012, 56, 3753-3757.

17 D. G. Brown and J. Boström, J. Med. Chem., 2016, 59, 4443-4458.

18 J. Boström, D. G. Brown, R. J. Young and G. M. Keserü, Nat. Rev. Drug Discov., 2018, 17, 709-727.

19 D. C. Blakemore, L. Castro, I. Churcher, D. C. Rees, A. W. Thomas, D. M. Wilson and A. Wood, Nat. Chem., 2018, 10, 383-394.

20 K. Bush and M. J. Macielag, Expert Opin. Ther. Pat., 2010, 20, 1277-1293.

21 J. D. Buynak, Expert Opin. Ther. Pat., 2013, 23, 1469-1481.

22 T. Stachyra, M.-C. Péchereau, J.-M. Bruneau, M. Claudon, J.-M. Frère, C. Miossec, K. Coleman and M. T. Black, Antimicrob. Agents Chemother., 2010, 54, 5132-5138.

23 S. D. Lahiri, S. Mangani, T. Durand-Reville, M. Benvenuti, F. D. Luca, G. Sanyal and J.-D. Docquier, Antimicrob. Agents Chemother., 2013, 57, 2496-2505.

24 A. Bonnefoy, C. Dupuis-Hamelin, V. Steier, C. Delachaume, C. Seys, T. Stachyra, M. Fairley, M. Guitton and M. Lampilas, J. Antimicrob. Chemother., 2004, 54, 410-417.

25 A. M. King, D. T. King, S. French, E. Brouillette, A. Asli, J. A. N. Alexander, M. Vuckovic, S. N. Maiti, T. R. Parr, E. D. Brown, F. Malouin, N. C. J. Strynadka and G. D. Wright, ACS Chem. Biol., 2016, 11, 864-868.

26 M. I. Abboud, C. Damblon, J. Brem, N. Smargiasso, P. Mercuri, B. Gilbert, A. M. Rydzik, T. D. W. Claridge, C. J. Schofield and J.-M. Frère, Antimicrob. Agents Chemother., 2016, 60, 5655-5662.
27 M. Lampilas, D. A. Rowlands, J. Aszodi, B. Musicki, P. Colette, Novexel, FR20010007520, 2001.

28 M. Lampilas, J. Aszodi, D. A. Rowlands, C. Fromentin, Aventis Pharma, US 2003/0199541, 2003.

29 H. C. Beyerman and P. Boekee, Recl. Trav. Chim. Pays-Bas, 1959, 78, 648-658.

30 F. E. King, T. J. King and A. J. Warwick, J. Chem. Soc. Resumed, 1950, 3590-3597.

31 A. Priour, A. Bonnet, G. Oddon, A. Mazurie, Novexel, WO2009090320, 2009.

32 M. Ball, A. Boyd, G. J. Ensor, M. Evans, M. Golden, S. R. Linke, D. Milne, R. Murphy, A. Telford, Y. Kalyan, G. R. Lawton, S. Racha, M. Ronsheim and S. H. Zhou, Org. Process Res. Dev., 2016, 20, 17991805.

33 T. Wang, L.-D. Du, D. Wan, X. Li, X.-Z. Chen and G.-F. Wu, Org. Process Res. Dev., 2018, 22, 1738-1744.

34 K. M. Papp-Wallace, M. D. Barnes, J. Alsop, M. A. Taracila, C. R. Bethel, S. A. Becka, D. van Duin, B. N. Kreiswirth, K. S. Kaye and R. A. Bonomo, Antimicrob. Agents Chemother., 2018, 62, e00174-18.

35 T. A. Blizzard, H. Chen, S. Kim, J. Wu, K. Young, Y.-W. Park, A. Ogawa, S. Raghoobar, R. E. Painter, N. Hairston, S. H. Lee, A. Misura, T. Felcetto, P. Fitzgerald, N. Sharma, J. Lu, S. Ha, E. Hickey, J. Hermes and M. L. Hammond, Bioorg. Med. Chem. Lett., 2010, 20, 918-921.

36 H. Chen, T. A. Blizzard, S. Kim, J. Wu, K. Young, Y.-W. Park, A. M. Ogawa, S. Raghoobar, R. E. Painter, D. Wisniewski, N. Hairston, P. Fitzgerald, N. Sharma, G. Scapin, J. Lu, J. Hermes and M. L. Hammond, Bioorg. Med. Chem. Lett., 2011, 21, 4267-4270.

37 T. A. Blizzard, H. Chen, S. Kim, J. Wu, R. Bodner, C. Gude, J. Imbriglio, K. Young, Y.-W. Park, A. Ogawa, S. Raghoobar, N. Hairston, R. E. Painter, D. Wisniewski, G. Scapin, P. Fitzgerald, N. Sharma, J. Lu, S. Ha, J. Hermes and M. L. Hammond, Bioorg. Med. Chem. Lett., 2014, 24, 780-785.

38 T. a Blizzard, H. Chen, C. Gude, J. D. Hermes, J. E. Imbriglio, S. Kim, J. Y. Wu, S. Ha, C. J. Mortko, I. Mangion, N. Rivera, R. T. Ruck and M. Shevlin, Merck \& Co Inc. WO 2009091856, 2009.

39 I. K. Mangion, R. T. Ruck, N. Rivera, M. A. Huffman and M. Shevlin, Org. Lett., 2011, 13, 5480-5483.

40 J. E. Baldwin, R. M. Adlington, C. R. A. Godfrey, D. W. Gollins and J. G. Vaughan, J. Chem. Soc. Chem. Commun., 1993, 1434-1435.

41 S. P. Miller, Y.-L. Zhong, Z. Liu, M. Simeone, N. Yasuda, J. Limanto, Z. Chen, J. Lynch and V. Capodanno, Org. Lett., 2014, 16, 174-177.

42 J. Yin, M. Weisel, Y. Ji, Z. Liu, J. Liu, D. J. Wallace, F. Xu, B. D. Sherry and N. Yasuda, Org. Process Res. Dev., 2018, 22, 273-277.

43 J. Y. L. Chung, D. Meng, M. Shevlin, V. Gudipati, Q. Chen, Y. Liu, Y. Lam, A. Dumas, J. Scott, Q. Tu and F. Xu, J. Org. Chem., , DOI:10.1021/acs.joc.9b02948.

44 S.-W. Yang, X. Linghu, E. Smith, J. Pan, V. Sprague and J. Su, Tetrahedron Lett., 2017, 58, 2838-2841.

45 Z. Edoo, L. Iannazzo, F. Compain, I. Li de la Sierra Gallay, H. van Tilbeurgh, M. Fonvielle, F. Bouchet, E. Le Run, J.-L. Mainardi, M. Arthur, M. Ethève-Quelquejeu and J.-E. Hugonnet, Chem. - Eur. J., 2018, 24, 8081-8086.

46 T. Abe, T. Furuuchi, Y. Sakamaki, S. Inamura, A. Morinaka, Meiji Seika Pahrma Co., Ltd JPWO2013180197, 2016.

47 S. N. Maiti, D. Nguyen, J. Khan and R. Ling, Naeja Pharmaceutical Inc., US20130225554, 2013.

48 A. Morinaka, Y. Tsutsumi, M. Yamada, K. Suzuki, T. Watanabe, T. Abe, T. Furuuchi, S. Inamura, Y. Sakamaki, N. Mitsuhashi, T. Ida and D. M. Livermore, J. Antimicrob. Chemother., 2015, 70, 2779-2786. 49 S. Mushtaq, A. Vickers, N. Woodford, A. Haldimann and D. M. Livermore, J. Antimicrob. Chemother., 2019, 74, 953-960. 
50 S. Joshi, S. B. Jadhav, V. Rane, S. Bhawsar, P. K. Deshpande, R. D. Yeole and M. V. Patel, Wockhardt Ltd.WO2015110885, 2015.

51 S. S. Pawar, S. B. Jadhav, A. C. Mishra, V. Rane, S. Bhawsar, P. K. Deshpande, R. D. Yeole and M. V. Patel, Wockhardt Ltd. US2016002234, 2016.

52 K. M. Papp-Wallace, N. Q. Nguyen, M. R. Jacobs, C. R. Bethel, M. D. Barnes, V. Kumar, S. Bajaksouzian, S. D. Rudin, P. N. Rather, S. Bhavsar, T. Ravikumar, P. K. Deshpande, V. Patil, R. Yeole, S. S. Bhagwat, M. V. Patel, F. van den Akker and R. A. Bonomo, J. Med. Chem., 2018, 61, 4067-4086.

53 M. Lampilas, D. A. Rowlands, A. Kebsi, B. Ledoussal and C. Pierres, Novexel, WO2008142285, 2008.

54 J. Comita-Prevoir, T. Durand-Reville, S. Guler, J. Romero, M. Sylvester, R. Tommasi, C. Velez-Vega, X. Wu and J. Zhang, Entasis Therapeutics Inc.,WO2018208769, 2018.

55 A. Casarez, M. Furegati, G. Koch, X. Lin, F. Ossola, F. Reck, R. L. Simmons and Q. Zhu, Novartis Ag US2018086762, 2018.

56 F. Reck, A. Bermingham, J. Blais, A. Casarez, R. Colvin, C. R. Dean, M. Furegati, L. Gamboa, E. Growcott, C. Li, S. Lopez, L. Metzger, S. Nocito, F. Ossola, K. Phizackerley, D. Rasper, J. Shaul, X. Shen, R. L. Simmons, D. Tang, K. Tashiro and Q. Yue, ACS Infect. Dis., 2019, 5, 1045-1051.

57 L. Chu, C. Ohta, Z. Zuo and D. W. C. MacMillan, J. Am. Chem. Soc., 2014, 136, 10886-10889.

58 H. Xiong, B. Chen, T. F. Durand-Réville, C. Joubran, Y. W. Alelyunas, D. Wu and H. Huynh, ACS Med. Chem. Lett., 2014, 5, 1143-1147.

59 B. M. Trost, D. B. Horne and M. J. Woltering, Angew. Chem. Int. Ed., 2003, 42, 5987-5990.

60 M. A. Allen, R. A. Ivanovich, D. E. Polat and A. M. Beauchemin, Org. Lett., 2017, 19, 6574-6577.

61 K. Shen and Q. Wang, Chem. Sci., 2015, 6, 4279-4283.

62 K. Shen and Q. Wang, Chem. Sci., 2017, 8, 8265-8270.

63 K. Shen and Q. Wang, J. Am. Chem. Soc., 2017, 139, 1311013116.

64 L. Peilleron, P. Retailleau and K. Cariou, Adv. Synth. Catal., 2019, 361, 5160-5169. 